\title{
Fermi National Accelerator Laboratory
}

FERMILAB-TM-2019

\section{D $\varnothing$ Rototrack: First Stage of $D \varnothing 2$ Tesla Solenoid Field Mapping Device}

R. Yamada, J. Korienek, J. Krider, C. Lindenmeyer, D. Miksa, R. Miksa

Fermi National Accelerator Laboratory

P.O. Box 500, Batavia, Illinois 60510

September 1997 


\section{Disclaimer}

This report was prepared as an account of work sponsored by an agency of the United States Government. Neither the United States Government nor any agency thereof, nor any of their employees, makes any warranty, expressed or implied, or assumes any legal liability or responsibility for the accuracy, completeness, or usefulness of any information, apparatus, product, or process disclosed, or represents that its use would not infringe privately owned rights. Reference herein to any specific commercial product, process, or service by trade name, trademark, manufacturer, or otherwise, does not necessarily constitute or imply its endorsement, recommendation, or favoring by the United States Government or any agency thereof. The views and opinions of authors expressed herein do not necessarily state or reflect those of the United States Government or any agency thereof.

\section{Distribution}

Approved for public release; further dissemination unlimited. 
TM 2019

D0 Note 3305

\title{
D0 Rototrack: First Stage of D0 2 Tesla Solenoid Field Mapping Device
}

\author{
R. Yamada, J. Korienek, J. Krider, C. Lindenmeyer, D. Miksa, R. Miksa
}

December 4, 1997

\begin{abstract}
A simple and portable field mapping device was developed at Fermilab and successfully used to test the D0 2 Tesla solenoid at Toshiba Works in Japan. A description of the mechanical structure, electric driving and control system, and software of the field mapping device is given. Four Hall probe elements of Group3 Digital Gaussmeters are mounted on the radial extension arm of a carriage, which is mounted on a central rotating beam. The system gives two dimensional motions (axial and rotational) to the Hall probes. To make the system compact and portable, we used a laptop computer with PCMCIA cards. For the control system we used commercially available software LabVIEW and Motion Toolbox, and for the data analysis we used Microsoft Excel.
\end{abstract}

\section{Introduction}

The D0 2 Tesla solenoid was made at Toshiba Works 1). Its central magnetic field is 2 Tesla. The overall length of the cryostat is $272.9 \mathrm{~cm}$ with its inside diameter as 106.7 $\mathrm{cm}$. The field measurement at Toshiba Works was intended to be carried out in the period of 16 hours, which was allocated for the endurance running test as a part of its acceptance test. Therefore the field measurement at Toshiba Works was not an extensive test, but was carried out to test the basic parameters of the solenoid. The test results from Toshiba Works are described in a separate report 2). This device will be modified for the final test at the D0 detector.

\section{Mechanical Structure of Field Measurement Device}

The whole mechanical structure of the light weight field measurement device is shown schematically in Fig. 1. An axial tube beam with a carriage is supported at both ends of the solenoid, and the Hall probe sensors are attached to the arm mounted on the carriage. The rotational motion of the beam and the axial motion of the carriage are controlled by two stepping motors through the extension pipe. The picture of the device attached to the dummy solenoid is shown in Fig. 2. The parts of the device which go into 
the solenoidal field volume are made of completely non-magnetic components, to prevent any eddy current effect in the event of a quench.

\subsection{Central beam and carriage with probe mounting arm}

The major mechanical structure of the field mapping device is a $4^{\prime \prime}$ square tube beam, made of carbon fiber, which is placed at the center axis of the solenoid cryostat with a support at each end. An extension arm, with four fixed Group 3 Digital Gaussmeter Hall probe, is mounted on a sliding carriage. The arm together with the Hall probes are rotated around the axis of the beam, and slid in the axial direction with two-axis microstepping motors and its controller made by Compumotor Co.

The central tube is made of a $4^{\prime \prime}$ square by $1 / 4^{\prime \prime}$ wall of Carbon Fiber/Epoxy Structural Tube, which is quite light and rigid. The tube is commercially available as a stock item from Airtech International Co. An 11' (=330 cm) long tube weighs $13.2 \mathrm{~kg}$. Its central deflection by its own weight is about $10 \mathrm{mils}(=0.25 \mathrm{~mm})$, and additional deflection due to a $2 \mathrm{lb}$ weight at its center is 1 mil. Its tensile modulus is $8.6 \times 10^{6} \mathrm{psi}$.

The central tube beam is supported at each end by an outwardly extended rigid structure with a plastic bearing at its center. The supporter is made of pieces of plastic pipes. The central tube is rotated remotely together with the long extension PVC pipe using a micro-stepping motor mounted at the far end of the pipe as shown in Fig. 1. A rotary encoder attached to this motor is used to register rotational angle. There is a mechanical provision to limit the rotation of the central beam not more than $360+10$ degrees.

A $2^{\prime \prime}$ square carbon fiber arm with Hall probes mounted at its end, travels along the central tube on a carriage. The carriage is pulled by a loop of string, made of Kevlar and controlled remotely by another micro-stepping motor mounted at the far end of the long extension pipe as shown in Fig.1. A rotary encoder attached to this motor is used to register $\mathrm{Z}$ position. The string is $1 / 16$ inch in diameter with a slightly braided Kevlar filament core, covered with braided Kevlar sheath. This string is made by Yale Cordale Inc.

\subsection{Geometrical constant of field measuring device}

The carriage rolls on the precisely machined surfaces of the beam, made of 4 " square carbon-fiber beam. A perpendicular arm, also made of 2" square carbon-fiber tube, is mounted on the carriage. The $\mathrm{z}$ axis of the measurement device is aligned relative to the inner circularly machined surfaces of both end flanges of the cryostat. Using a dial gauge, which is mounted at the end of the arm on the carriage, the beam can be set within $0.25 \mathrm{~mm}$ (10 mils) relative to the circular surface .

On the top of the arm, a precision machined Noryl probe holder is mounted. One $\mathrm{Bz}$ probe; Bzt, and two $\mathrm{Br}$ probes, $\mathrm{Br} 1$ and $\mathrm{Br} 2$, (which are displaced in radial direction by $5.5 \mathrm{~mm}$ ) are mounted on this probe holder. They are mounted precisely perpendicular to the Z-axis and R-axis of the $4^{\prime \prime}$ square central carbon fiber tube beam. Three probes are mounted together on a small cubic probe holder, and were aligned precisely using a 
standard magnet. Another Bz probe; Bzb, is mounted at the bottom of the 2 " square tube to measure the near central field distribution along the $\mathrm{z}$-axis. Their geometrical relation is shown in Fig. 3, and given in Table I.

\section{Table I Geometrical relation of Hall probes}

\begin{tabular}{|c|c|c|c|c|}
\hline Radial Position (cm) & $\begin{array}{l}\text { Outer Radial } \\
\text { Probe: } \mathrm{Br} 1 \\
52.25\end{array}$ & $\begin{array}{c}\text { Inner Radial } \\
\text { Probe: } \mathrm{Br} 2 \\
51.7\end{array}$ & $\begin{array}{c}\text { Top Z } \\
\text { Probe Bzt } \\
50.4\end{array}$ & $\begin{array}{l}\text { Bottom Z } \\
\text { Probe: Bzb } \\
10.2\end{array}$ \\
\hline $\begin{array}{l}\mathrm{Z} \text { position }(\mathrm{cm}) \text { of probe, } \\
\text { when placed at } \\
\text { the edge of the cryostat }\end{array}$ & 27.1 & 27.1 & 27.8 & 31.1 \\
\hline $\begin{array}{l}\text { Relative } \mathrm{Z} \text { position }(\mathrm{cm}) \\
\text { to radial probes }\end{array}$ & 0 & 0 & -0.7 & -4.0 \\
\hline
\end{tabular}

To cancel the effect of fluctuation and drift in current, a reference Hall probe is mounted on the inner central surface of the cryostat, where the field value is 2 Tesla. The readings of all other probes will be normalized to this reference probe.

\section{Control System}

The block diagram of the overall control system is shown in Fig 4. The Group 3 Digital Gaussmeters are used to record the magnetic fields with high precision. The electrical and mechanical systems are controlled with a program "Roto30", which was developed by our group utilizing LabVIEW from National Instruments, and a LabVIEW based program Motion Toolbox from Compumotor. "Roto30" runs on a portable laptop computer with a PCMCIA card for the GPIB control of the Digital Gaussmeters. A serial port on the computer is used for stepping motor control. The data from "Roto30" are stored on the hard disk of the laptop computer,and can be analyzed with Microsoft Excel software.

To design the system we used the following principles.

1. To minimize software development effort, we used the commercial graphically based program "LabVIEW".

2. To effectively use the capability of the program "LabVIEW", we chose hardware which was either directly controlled by LabVIEW or had its own software compatible with LabVIEW.

3. For the computer system, we selected a laptop portable with PCMCIA card to minimize interface effort. This eliminated the need for developing hardware and software for the interface.

\subsection{System hardware}

The basic block diagram of the system is shown in Fig. 4. The system is centered around a portable computer, which controls the two micro-stepping motors, reads the two 
position encoders, and the five Hall probes. The mechanical control system is made up of two major components, a laptop computer and a two axis stepping motor controller model 6201 from Compumotor Division of Parker Hannifin Corp. The laptop is a Toshiba Pentium $120 \mathrm{MHz}$ computer "Tecra 500" operating LabVIEW.

The RS-232 serial port of the computer communicates with the Compumotor two axis motion controller. Attached to the motion controller is a limit switch control box that keeps the system within working ranges, and provides homing status with use of limiting switches. The information of these switches is passed from the controller to the computer where they can be monitored at all times. For the mechanical operation, the program Motion Toolbox, which is written based on LabVIEW and provided by Compumotor, is utilized in our Roto30 program.

These micro-stepping motors have a resolution of 25,000 steps per rotation. In our normal operations, we move the carriage at the speed of $\approx 5 \mathrm{~cm} / \mathrm{sec}$, and the beam at the rotational speed of $\approx 6$ degrees/sec. There is no observable vibration of the system with these micro-stepping motors.

The computer also controls 5 Hall probes through a PCMCIA card for GPIB control. Digital outputs of the Hall probes are read into the PC through a National Instrument GPIB PCMCIA card, and processed on-line. The calculated field distributions are also displayed on-line.

\subsection{Gaussmeters}

The Gauss-meters are made by Group 3. They are model DTM-141 Digital Teslameters with GPIB interface. LPT-141 probes are used. The ranges are 3.0, and 1.2 Tesla full-scale, and resolution is 1 in 60,000 of full scale (16-bit digitizing). With this set of combination, the precision is $\pm 0.01 \%$ of reading, $\pm 0.006 \%$ of full scale max. $( \pm 3.0$ and \pm 1.2 Gauss for 3 and 1.2 Tesla range).

The zero drift is $\pm(0.01$ Gauss $+0.0003 \%$ of full scale $) / C$, and add $-3 \mathrm{ppm} / \mathrm{C}$ for each meter of probe cable. With a $20 \mathrm{~m}$ probe cable and at $1.2 \mathrm{~T}$ range, it is about -0.8 Gauss/C. The time stability is $\pm 0.1 \%$ maximum over 1 year.

The maximum environmental operation field for the instrument with a multi-range probe is 5 Gauss. Therefore we have to be careful about the fringing field value, where we put the Teslameters. We used an iron shielding box for each unit. (With single-range probe it is 100 Gauss.) The probe is calibrated at the factory. The sensitivity area of the probe is $4.0 \mathrm{~mm} \times 1.8 \mathrm{~mm}$.

The Digital Teslameter has $120 \mathrm{~ms}$ settling time, and it takes $200 \mathrm{~ms}$ to read out data into the computer. With 5 units it takes the total of $\approx 600 \mathrm{~ms}$ to read out all information.

\section{Software}

The main software component is LabVIEW from National Instruments. This software is a graphical computer programming language that interfaces with many different hardware devices on the market. In conjunction with this software we use 
Motion Toolbox, which is a software package written by Compumotor, designed in LabVIEW to allow communication with the two axis motion controller for their microstepping motors. This allows total control of the system by LabVIEW.

\subsection{Roto30}

The program called Roto30 was developed for this field mapping device using LabVIEW and Motion Toolbox. This program is menu driven and works in the following different modes.

1. Interactive Mode: Take data values at specified place

2. Standard Mode: Do continuous data taking in the linear mode in $\mathrm{Z}$ direction, or in the rotational mode. In this mode the user enters a specified starting position and ending position in $\mathrm{cm}$. From here the program will do the rest of the work.

3. Setup Mode: Menus that allow the user to enter specific parameters for the actual field mapping, like changing GPIB parameters.

The block diagram for Roto30 is shown in Fig. 5. The main part of Roto30 in the LabVIEW program is shown in Fig. 6. The detailed description and operating instructions for Roto30 is described in the "D0-Roto-Track Manual" 3).

Once the program is started in the standard data taking mode, it follows the following steps.

1. Initializing the motion controller and the GPIB communication to the Group 3 Digital Teslameters.

2. It then prompts the user for a particular mode in which to operate.

3. Once the mode and parameters are selected by the user, then the program moves the mechanical carriage to the home position.

4. Now the program begins moving the carriage to the location the user specified if in the interactive mode, or begin moving to all the specific locations if in the standard mode.

5. In the standard mode the carriage moves along that path and then returns to the beginning position, taking data in both directions.

6. At each step the carriage moves to a position, stops, takes a measurement and then begins to move to the next point. During this time the computer stores the data to its hard disk. The computer also displays graphic information to the monitor so that the user can watch the mapping in progress.

7. When done the user can choose to return to the main menu and begin again.

The main graphical display is used also to show the status of the mapping during data taking process. On this display are indicators that let the user know what is happening at all times. Indicators such as the following are included,

1. Limit lights to tell if the carriage has reached the linear or rotational limit. 
2. Homing indicators to tell when the carriage is in the proper starting position.

3. Motion indicators to indicate which axis is moving.

4. Indicators to show when in position or not.

5. Position indicators to show where the arm is located inside the solenoid.

All data are stored on the hard drive in a file that the user has specified. The data are stored in a format that can be used by Excel for further analysis.

\subsection{Typical parameters used for measurement}

The carriage moves along the beam at $5 \mathrm{~cm} / \mathrm{sec}$. The beam is rotated at $6 \mathrm{deg} / \mathrm{sec}$. The reading time of the Group 3 Digital Gaussmeter is $300 \mathrm{~ms}$ for each channel, including its settling time. After each stopping, an additional $200 \mathrm{~ms}$ is spent before moving to the next point. For data taking with 5 probes, $300 \mathrm{~ms}+200 \mathrm{~ms}=500 \mathrm{~ms}$ or $600 \mathrm{~ms}$ is spent at a point. The acceleration and deacceleration are set at $1 \mathrm{~cm} / \mathrm{sec}^{2}$, and 1 degree $/ \mathrm{sec}^{2}$. Typically it takes $5 \mathrm{~min}$ to take data at $5 \mathrm{~cm}$ steps over $300 \mathrm{~cm}$ one way, and $5 \mathrm{~min}$ to take data at 5 degree steps over 350 degree rotation in one way.

\subsection{Graphical display of Roto30}

A typical final display with Roto30 is shown in Fig. 7. On the left end side the conditions of the operation are shown. On the right end side the marking of the graphs are shown. In the central upper window, the on-line data are shown during a run. The data was taken during the D0 2.08 Tesla solenoid test at Toshiba. The values of Bzt, Bzb, $\mathrm{Br} 1$ and $\mathrm{Br} 2$ are displayed as on-line. When the run is complete, the same display result is shown in the central bottom window.

\section{Geometrical Survey of $4^{\prime \prime}$ Square Beam and Carriage Movement}

The straightness of the 4" square beam and the carriage movement over the length of the $320 \mathrm{~cm}$ was surveyed by Fermilab survey group. We used a Coordinate Measuring Machine (CMM), Chesapeak CMS-3000, which uses a laser beam to measure distance and displacement. The errors due to this instrument alone are $\pm 0.025 \mathrm{~mm}$ in $\mathrm{x}, \mathrm{y}$, and $\mathrm{z}$ directions.

On the carriage, we installed 3 spherical targets, which were temporally glued to an extension plate on the carriage to avoid the effects of slack movement of the targets.

The positions of the targets in $\mathrm{x}$, (positive: to the left when looking from the south), $\mathrm{y}, \mathrm{z}$ were measured at $10 \mathrm{~cm}$ steps in the forward and backward directions. The $4^{\prime \prime}$ square beam, together with the carriage, was found straight within $\pm 0.1 \mathrm{~mm}$ and \pm 0.2 $\mathrm{mm}$ in $\mathrm{x}$ and $\mathrm{y}$ direction as shown in Fig 8 and 9 . The variation in the $10 \mathrm{~cm}$ step distance in the $\mathrm{z}$ direction was found $\pm 0.2 \mathrm{~mm}$, which is shown in Fig. 10, excluding both ends.

The backlash in $\mathrm{z}$ direction, when the direction of motion is changed is about 6 $\mathrm{mm}$. The main cause of the backlash is in the gearing mechanism, and we think we have to install anti-backlash gears. There is some contribution from stretching of the Kevlar cable. 


\section{Magnetic Field Calculation}

Using Biot-Savart's law, the magnetic field components $\mathrm{Bz}$ and $\mathrm{Br}$ at any point in or out of the solenoid without any ferromagnetic material, can be calculated with Program BZBR0. The magnetic field components at that point from all turns of both layers, are summed. The effect of two kinds of conductors, which are used in the D0 solenoid, and the effect of joints are considered. Using that program as a subroutine, the distribution of magnetic field components along the length of the Z-axis is calculated by the Program BZBR_ZRANGE. It is written in FORTRAN with Double Precision, and their simple explanation together with the input and output data are explained in Appendix A.

The field distributions of $\mathrm{B}, \mathrm{Bz}$, and $\mathrm{Br}$ are calculated at $\mathrm{R}=51$ and $52 \mathrm{~cm}$ and shown in Fig. 11. At $R=52 \mathrm{~cm}$ it is $1.3 \mathrm{~cm}$ away from the inner surface of the cryostat which is at $\mathrm{R}=53.3 \mathrm{~cm}$. The radial position of the inner and outer conductor are 58.97 and $60.57 \mathrm{~cm}$ respectively. In $\mathrm{Z}$ direction the edges of the conductor and the cryostat in the following calculation are assumed at $\mathrm{Z}=126.62$ and $136.5 \mathrm{~cm}$ respectively. (Dimensions used in the this calculation are slightly different from the final dimensions.)

\section{What can be measured with this instrument}

In the following we listed major magnetic characteristics which can be studied with this field mapping device.

\subsection{Field distribution along $\mathrm{Z}$ axis}

With the present setup it is not possible to mount a Hall probe on the Z-axis. The nearest mounting position is about $10 \mathrm{~cm}$ from the z-axis, as shown in Fig. 3 for the probe Bzb.

\subsection{Exact $Z$ positions of averaged edge of conductor layers at both ends}

The $\mathrm{Br}$ distributions at $\mathrm{R}=51$ and $52 \mathrm{~cm}$ are shown in Fig. 11. Its expanded distribution near the conductor edge at $\mathrm{z}=126.62 \mathrm{~cm}$ is shown in Fig. 12 together with $\mathrm{B}$ and $\mathrm{Bz}$ distribution. By measuring the distribution of the $\mathrm{Br}$ component near the edge of the conductor at $\mathrm{R}=52 \mathrm{~cm}$, we are able to determine the conductor edge within $1 \mathrm{~mm}$. We look for the position of its maximum value, and we will measure its edge positions at different azimuthal angles on both ends.

The exact $\mathrm{Z}$ position of the edge of the conductor layer can be determined from the display of $d B r / d z$. The $d B r / d z$ and $d B z / d v$ distributions at $\mathrm{R}=52 \mathrm{~cm}$ around the conductor edge at $Z=126.63 \mathrm{~cm}$, are shown in Fig. 13 and 14. On the curve we can determine the $\mathrm{Z} 0$ value, where the curve will cross the zero value. Practically by measuring $\mathrm{Br}$ at 10 points over $10 \mathrm{~cm}$ region centered at $\mathrm{Z} 0$, we should be able to determine the edge position with accuracy of $1 \mathrm{~mm}$ or better. The difference between Z0 and the actual edge point depends on their radial displacement, which can be calculated 
and corrected. In Fig. 14 the $\mathrm{Z} 0$ point is about $2 \mathrm{~mm}$ outside from the conductor edge line. The precision of the Hall probe is 1.2 Gauss for the 1.2 Tesla range.

\subsection{Relative $R$ positions of average edge of conductor layers at both ends at different phi angles}

The relative radial positions of the conductor layers at both ends can be determined from the absolute peak values of $\mathrm{Br}$ components. $d B r / d r$ has the sensitivity of about 57 Gauss/mm for radial direction at $\mathrm{R}=52 \mathrm{~cm}$ as shown in Fig. 13. By rotating the $2^{\prime \prime}$ square arm with $\mathrm{Br}$ Hall probes mounted at a fixed $\mathrm{Z}$ position, we can measure the eccentricity of the conductor layers from the geometrical center of the cryostat.

At $\mathrm{Z}=\mathrm{Z} 0$ position, $\operatorname{Br}(\mathrm{z})$ is 9568 Gauss and at its maximum. At that position $\mathrm{dBr} / \mathrm{dr}$ is $568 \mathrm{Gauss} / \mathrm{cm}$ in radial direction. For a radial displacement of $1 \mathrm{~mm}$, this corresponds to 57 Gauss. This difference of 57 Gauss is $6 \times 10^{-3}$ of $\mathrm{Br}$, and can be easily detected with the Hall probe, which has a precision of 1 Gauss. By rotating the arm, the eccentricity of the conductor cylinder can be measured.

In the cylindrical coordinate

$$
\begin{gathered}
\operatorname{div} B=1 / r \cdot(\partial(r B r) / \partial r)+1 / r(\partial B \vartheta / \partial \vartheta)+(\partial B z / \partial z)=0 . \\
\text { If }(\partial B \vartheta / \partial \vartheta)=0, \\
\partial B r / \partial z=\partial B r / \partial r-1 / r \cdot B r .
\end{gathered}
$$

In Fig. 13 the values of $\partial B r / \partial r$ and $\partial B z / \partial z$ satisfies the above equation with $\mathrm{R}=52 \mathrm{~cm}$ and $\mathrm{Br}=9600$.

\subsection{Average angle of magnetic axis of solenoid relative to geometric axis}

By measuring the $\mathrm{Z}$ and $\mathrm{R}$ positions of the conductor edges at both ends and at different azimuthal angles, we can determine the inclined angle of the magnetic axis from the geometrical axis of the cryostat. At both ends $(Z= \pm 126.62 \mathrm{~cm})$, the position of the magnetic axis can be determined with accuracy of $1 \mathrm{~mm}$. With the distance of $253 \mathrm{~cm}$ between them, the detection accuracy of the magnetic axis's tilting is $\pm 1 / 2530 \mathrm{rad}$ $= \pm 0.4 \mathrm{mrad}$.

\subsection{Extract $Z$ positions of joints of conductor}

At the joints of the conductor, two different conductors are wound together into a single whole trun, effectively loosing a turn. The positions where two different types of conductor are jointed can be observed from the field distributions of $\mathrm{Bz}$ and $\mathrm{Br}$. The calculated $\mathrm{Bz}$ distributions are shown in Fig. 15 and 16 together with the locations of the joints. The calculated $\mathrm{Br}$ distributions around the joint in the center layer is shown in Fig. 17. 


\subsection{Magnetic center and uniformity of winding}

By comparing the field distributions at the south and north halves, we can determine the uniformity of the winding.

\section{$\underline{\text { Acknowledgments }}$}

We acknowledge the skillful mechanical construction done by our machinists at the central machine shop and also by D. Booth. The survey data were taken and analyzed by Fermilab Survey Group. We also appreciate discussions and suggestions from S. Pordes, H. Jostlein, H.E. Fisk, and R. Smith.

\section{References}

1. "Conceptual Design of a 2 Tesla Superconducting Solenoid for the Fermilab D0 Detector Upgrade”, J. Brzezniak et. al., May 13, 1994. Fermilab TM 1886.

2. "Magnetic Field Measurement of 2 Tesla D0 solenoid at Toshiba Works", R.Yamada, H.F. Fisk, D.Miksa and R.P. Smith, Aug, 1997, to be issued as a Fermilab TM.

3. “D0-Roto-Track Manual” D. Miksa, 1996.

\section{Appendix A Programs BZBR_ZRANGE and BZBR0}

\section{Program BZBR_ZRANGE}

BZBR_ZRANGE.FOR;33 calculates BZ, BR (=BX), B at $(Z, R)$ for the D0 2Tesla solenoid for input range of $\mathrm{ZIN}(1)$ to $\mathrm{ZIN}(2)$ in step of ZSTEP using subroutine BZBR0(Z,R,BZ,BR).

To set $\mathrm{Bz}(0,0)=20,000$ Gauss, Current is set to 4643.705 Amps

Calculates Sensitivity $\mathrm{dBZ} / \mathrm{dz}, \mathrm{dBZ} / \mathrm{dr}, \mathrm{dBR} / \mathrm{dz}, \mathrm{dBR} / \mathrm{dr}$ for Small Increment $\mathrm{dz}$ and $\mathrm{dr}$ (e.g. $1 \mathrm{~mm})$.

Then Plots BZ, BR, or dBZ, dBR in Step of dZ, using program TOPDRAWER

Input data: ZIN(1), ZIN(2), ZSTEP, dz, and dr in $\mathrm{cm}$

Output data: FILE='BZBR_SENSIT.DAT'

This contains Input Data for TDD Graphic 


\section{Subroutine BZBR0(Z,R,BZ,BX)}

Subroutine BZBR0(Z,R,BZ,BX) calculates field components Bz \& Br for 2-Tesla $\mathrm{D} 0$ solenoid. It calculates $\mathrm{BZ}(\mathrm{R}, \mathrm{Z})$ and $\mathrm{BR}=\mathrm{BX}$ (on $\mathrm{Y}=0$ plane) using BiotSavart's law,

$$
\begin{aligned}
& d \vec{H}=I *[d \$ \times \vec{D} i s t] /\left(10 *|\vec{D} i s t|^{3}\right) \quad \text { I: Amp } H: \text { Oersted } \\
& \mathrm{d}(\mathrm{Bz})=d \vec{H} \bullet \vec{k} \\
& \mathrm{~d}(\mathrm{Bx})=d H \bullet \vec{i} \\
& d \overline{\$}, \text { Dist: in cm }
\end{aligned}
$$

UNIT:: LENGTH: cm, ANGLE: radian

Input data: $\mathrm{R}(=\mathrm{X}), \mathrm{Z}: \mathrm{cm}$

Output data: BZ, BX (=BR), Btot :Gauss 


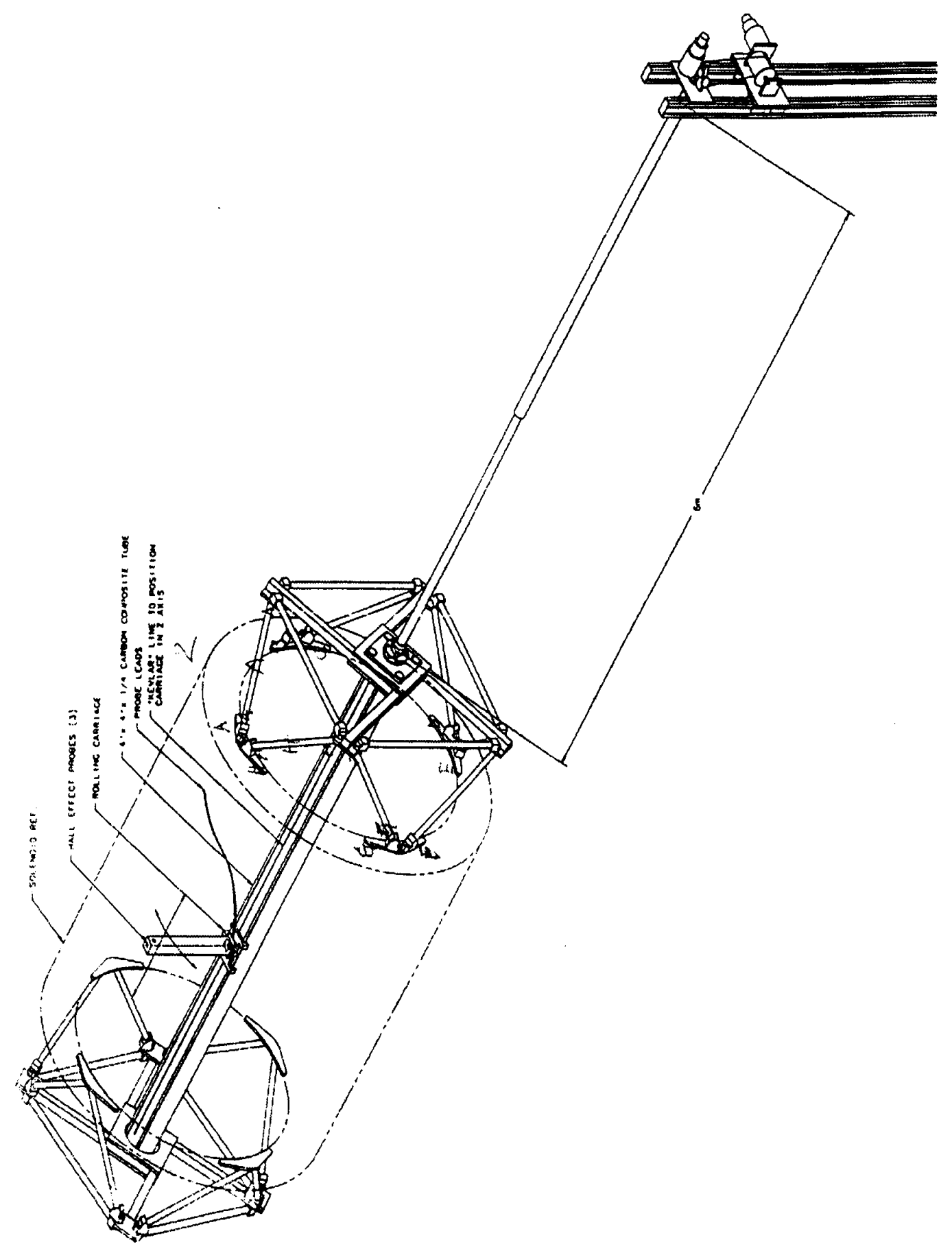

Fig. 1 The whole structure of the light weight field measurement device 


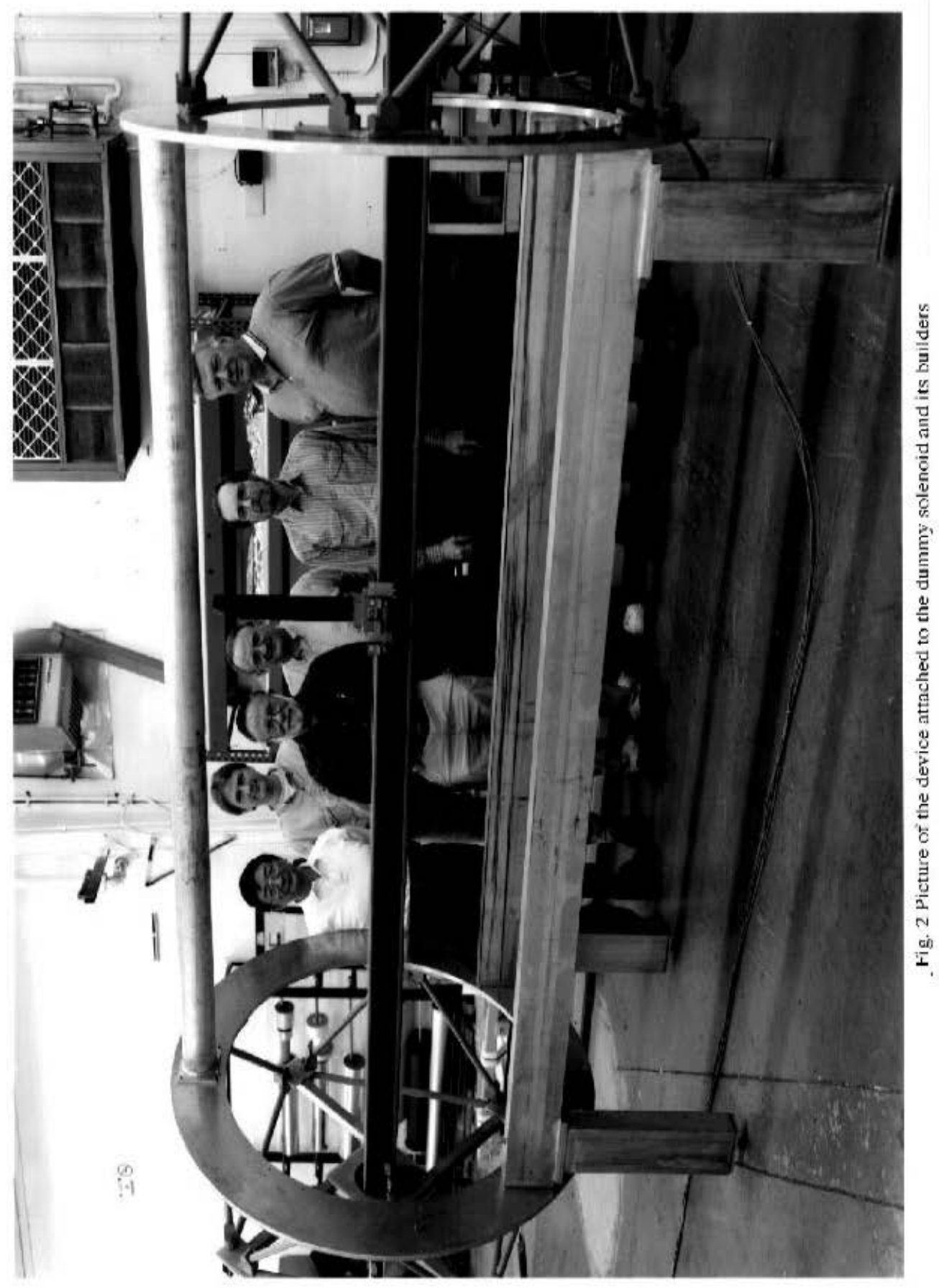




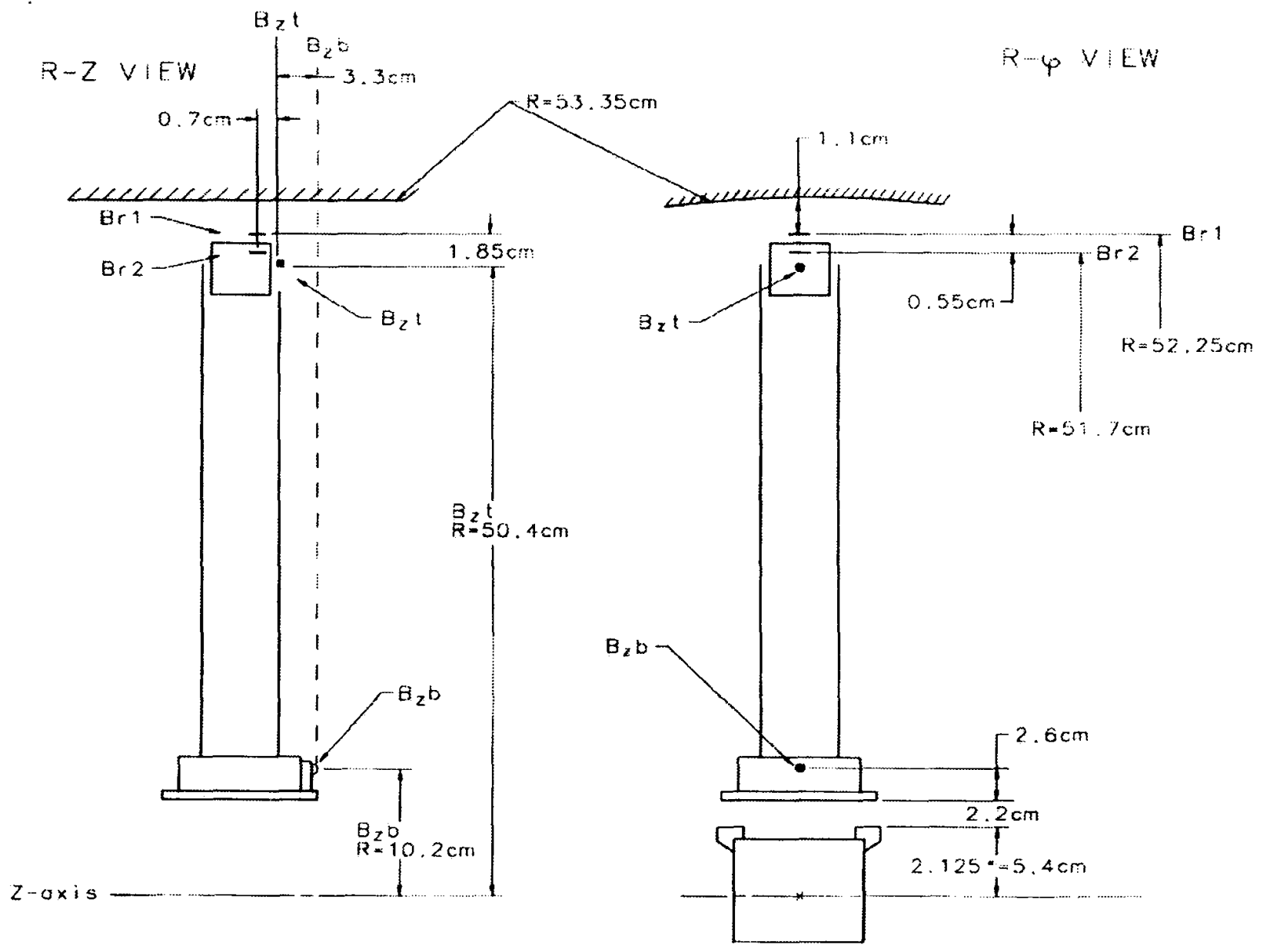

Fig. 3 Geometricl Settings of Hall Probes. Postitions of 2 vertical probes Bzt and Bzb. and 2 radial probes Br1 and Br2 are shown 


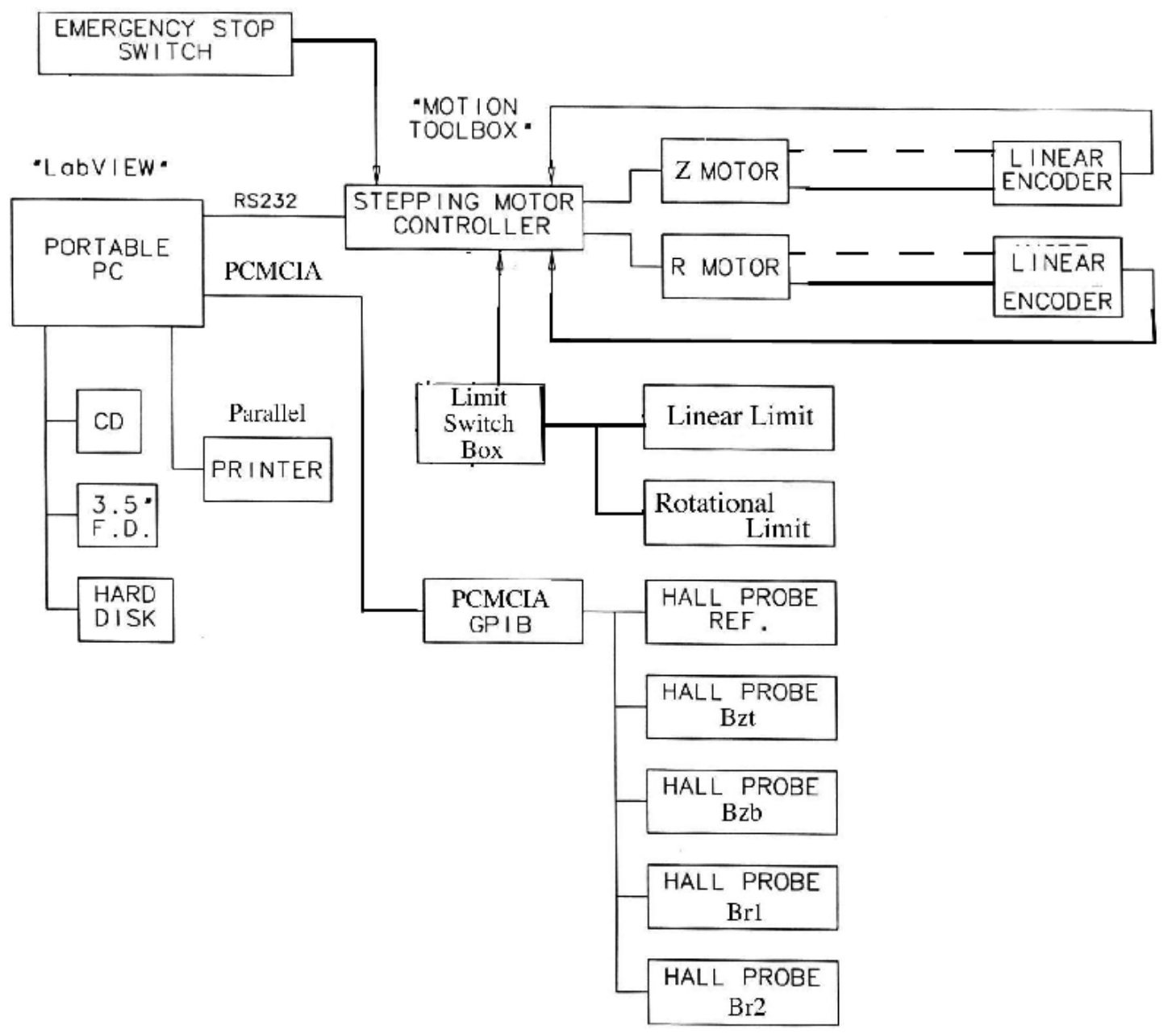

Fig. 4 Basic Block Diagram of overall hardware system 


\section{Basic Instruction Diagram}

December 3, 1996

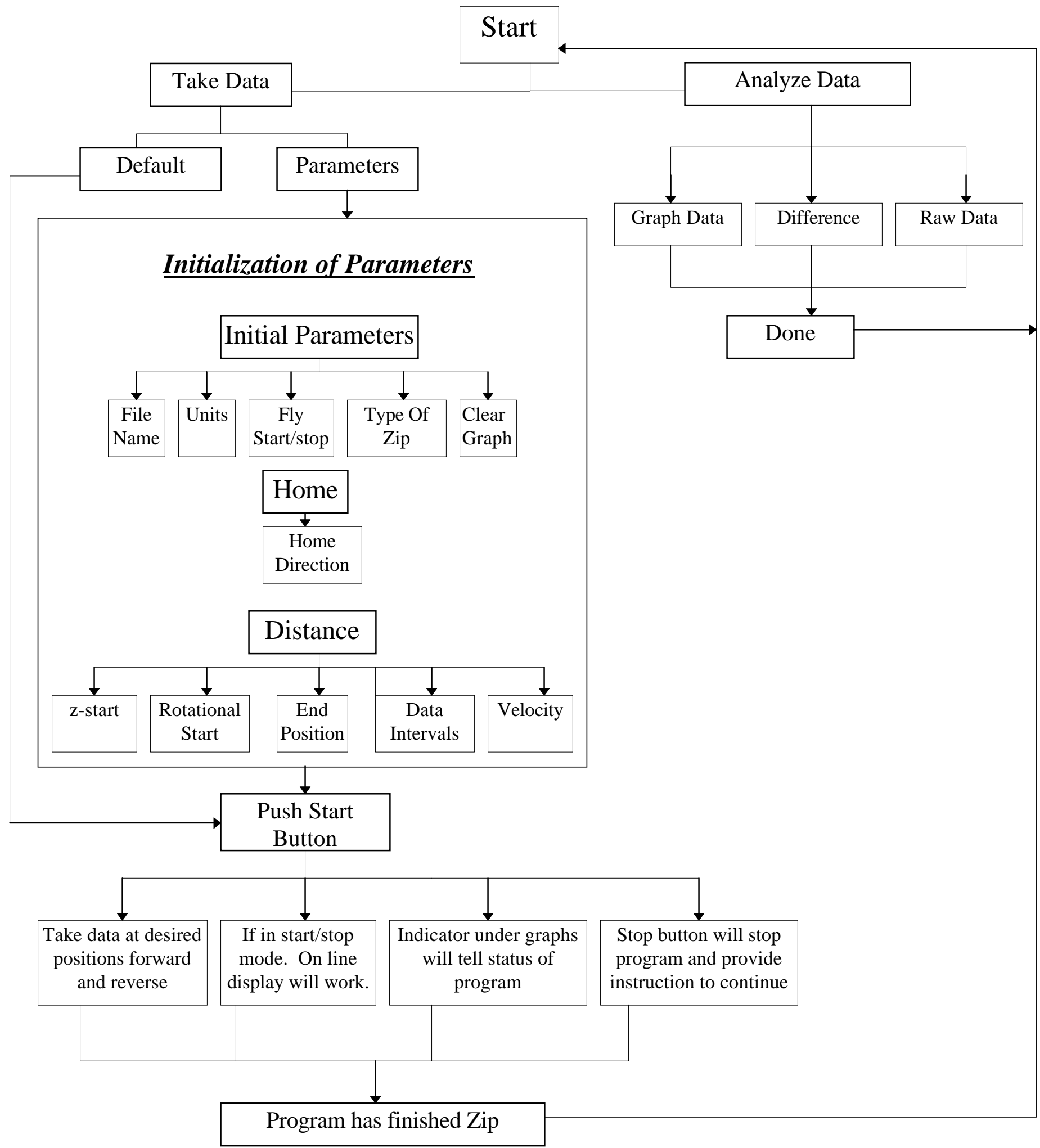

Fig. 5. Basic Block Diagram 
roto30.vi

Page 2 量

Last modified on 1/6/97 at 7:07 PM

Block Diagram

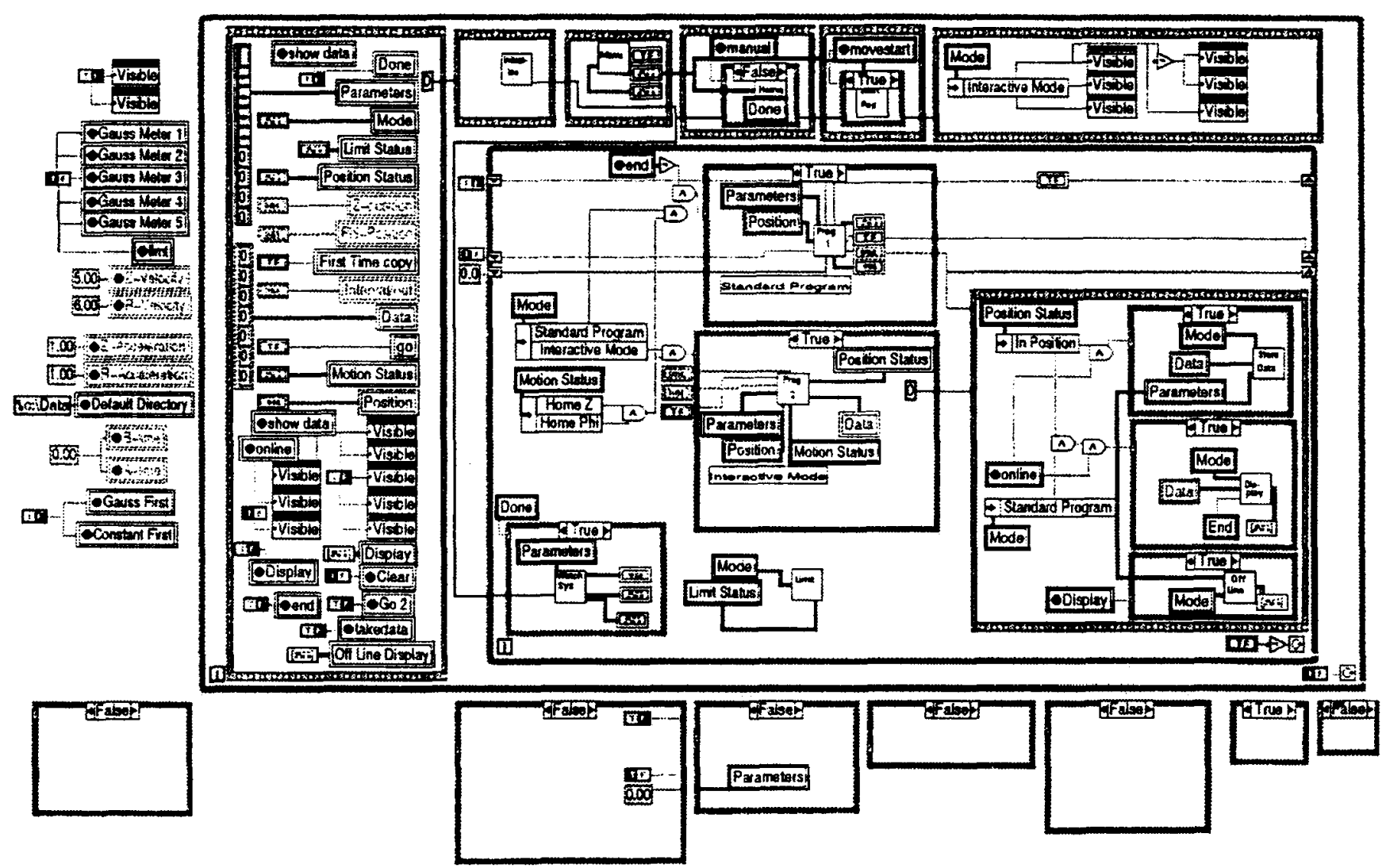

Fig. 6 The main part of Roto30 in the LabVIEW program 


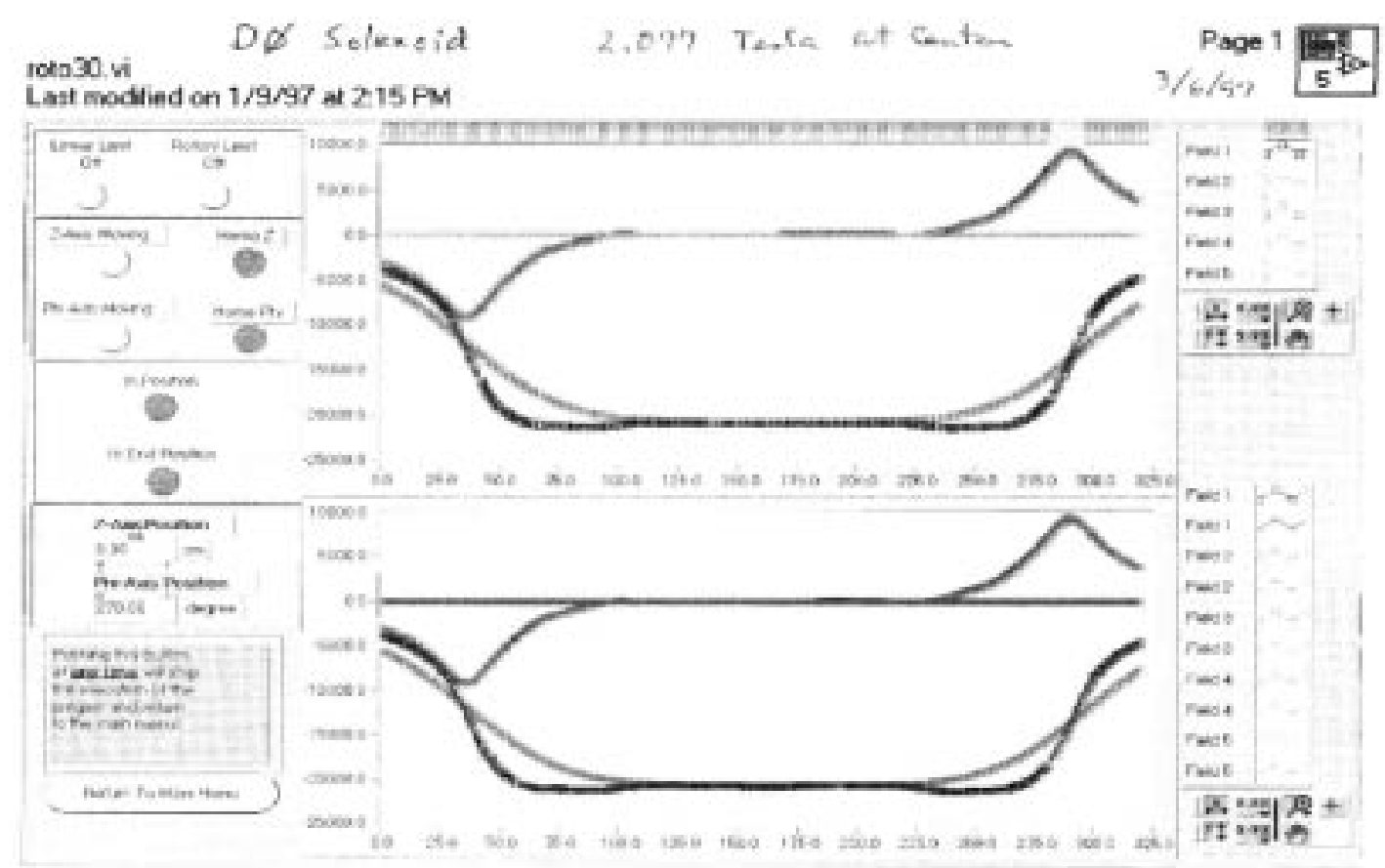

Fig. 7 Final Display of the on-line data taking with LabVIEW. Data shows the field distributions of $\mathrm{Bzt}, \mathrm{Bzb}$, and $\mathrm{Br} 1$ and $\mathrm{Br} 2$ probes along the length of $2 \mathrm{~T}$ solenoid, when the solenoid was excited up to 2.08 Tesla.

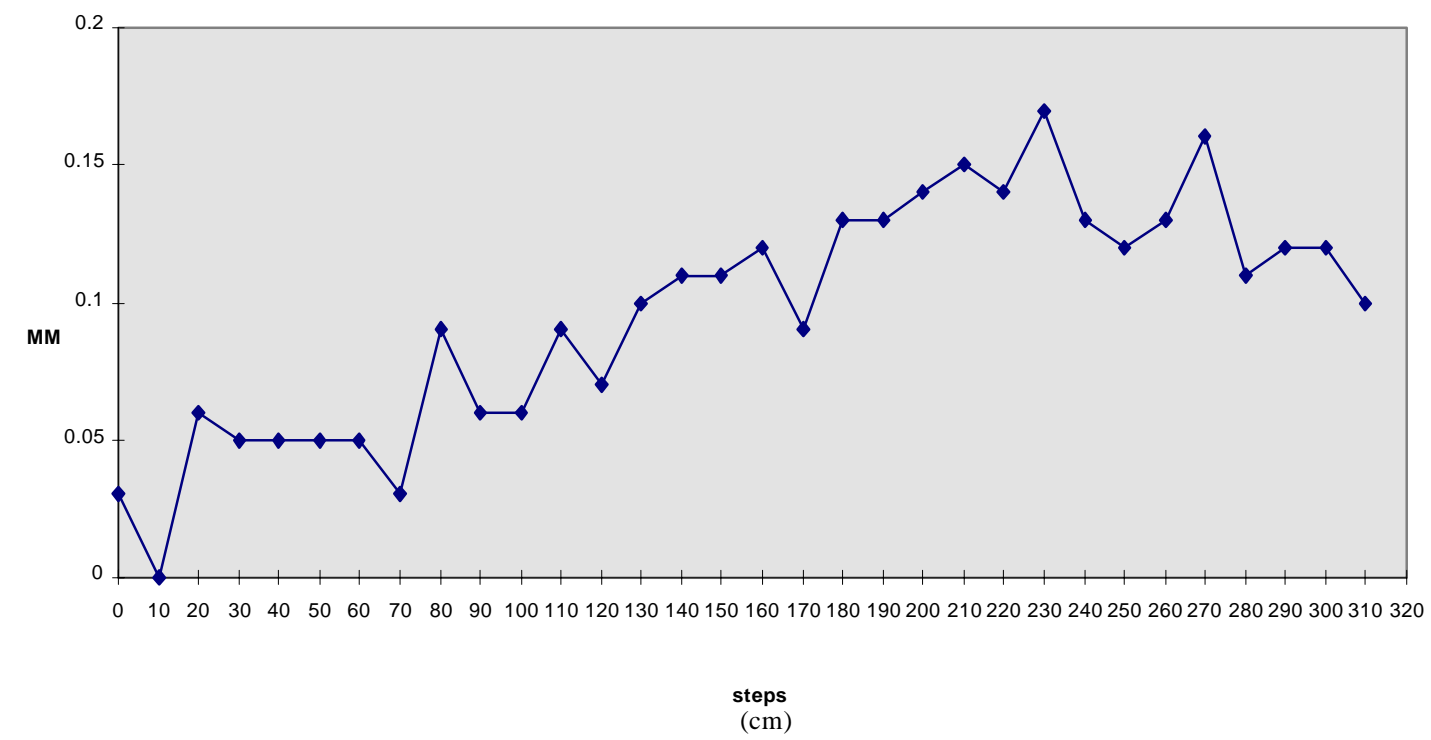

Fig. 8 Absolute displacement of the carriage in $\mathrm{X}$-direction during the forward $10 \mathrm{~cm}$ step motion. 


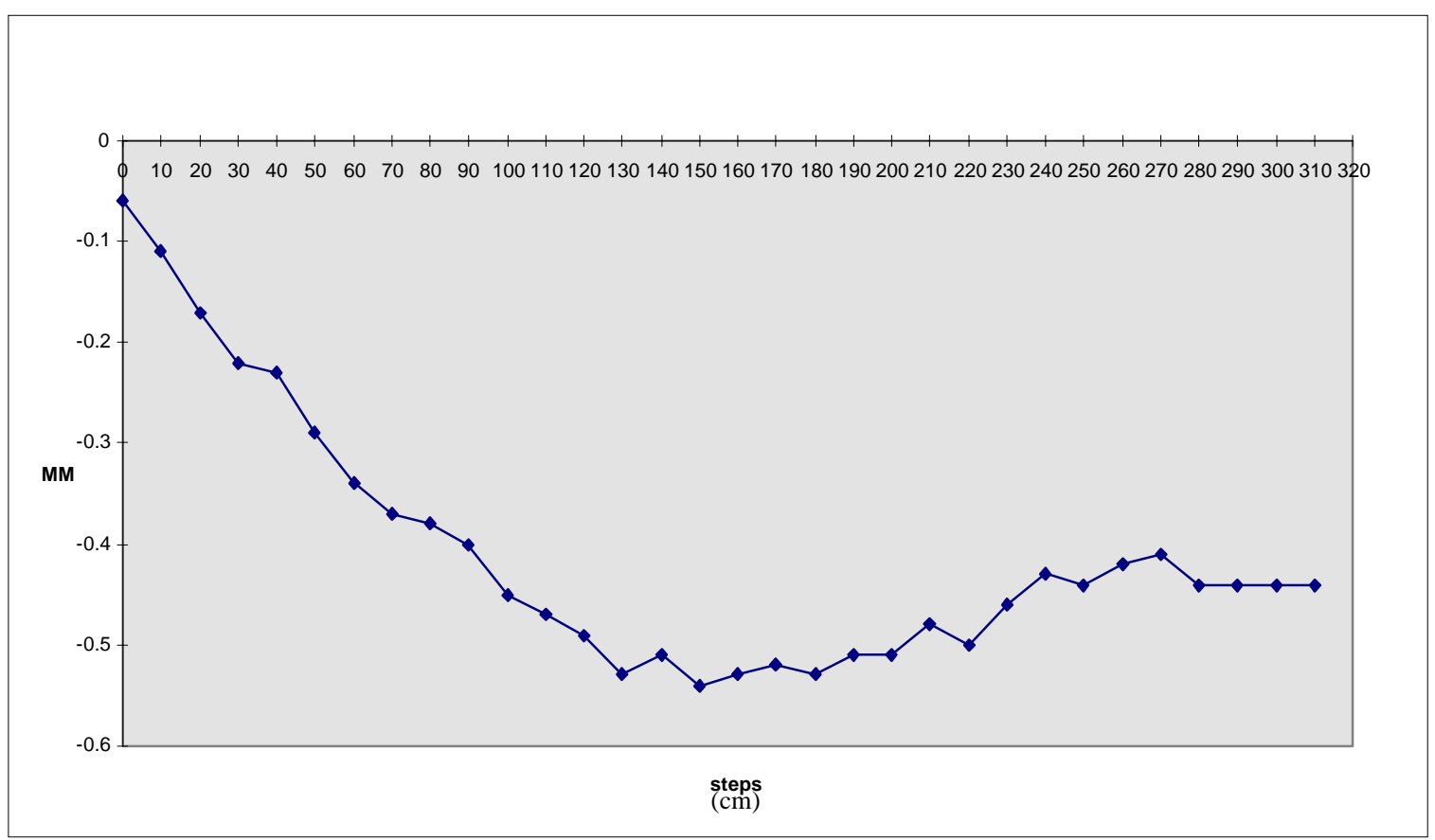

Fig. 9 Absolute displacement of the carriage in $\mathrm{Y}$ - direction during the forward $10 \mathrm{~cm}$ step motion

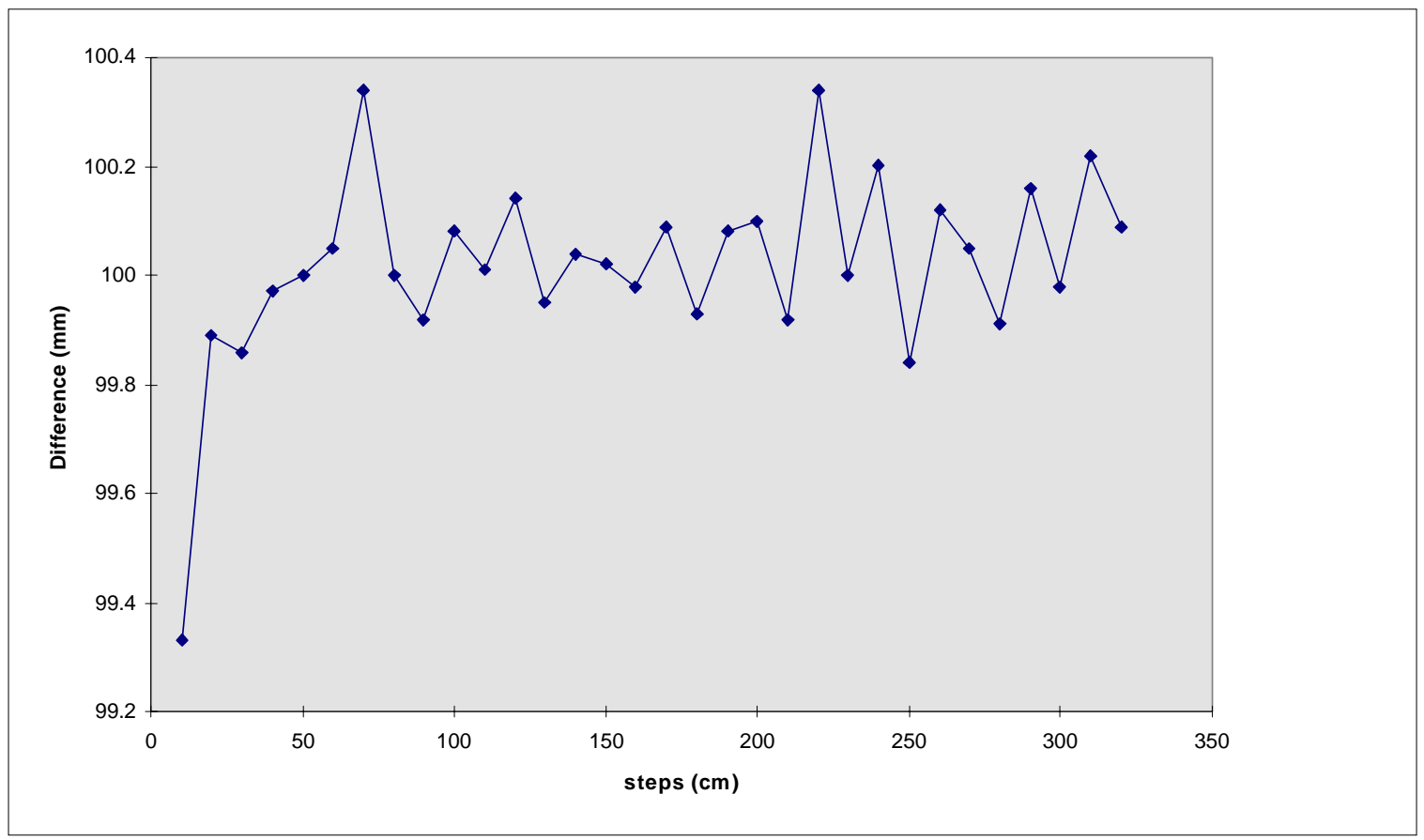

Fig. 10 Variation in the step distance of the carriage in Z-direction during the forward $10 \mathrm{~cm}$ step motion. 


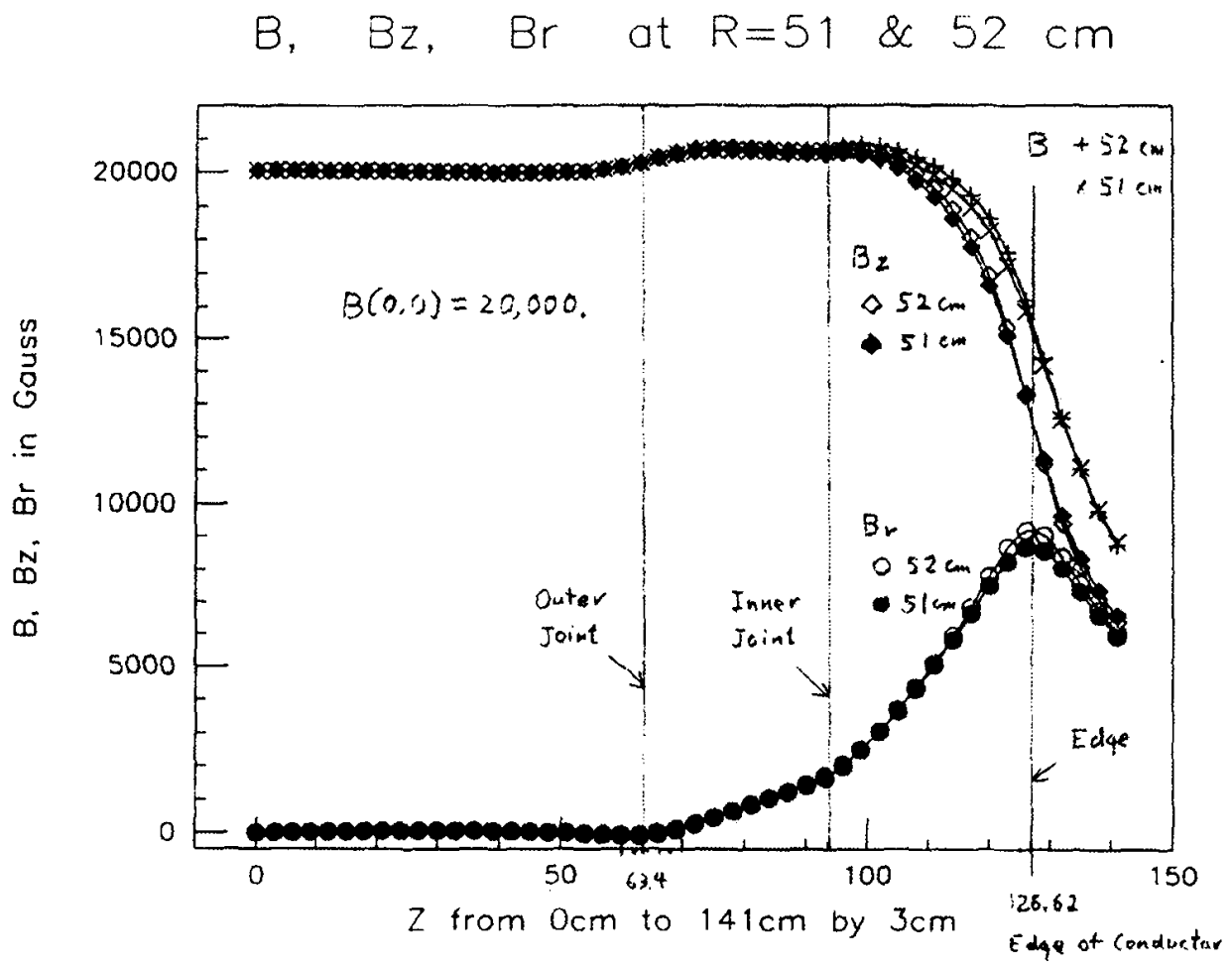

Fig. $11 \mathrm{~B}, \mathrm{Bz}$, and $\mathrm{Br}$ distribution at $\mathrm{R}=51$ and $52 \mathrm{~cm}$

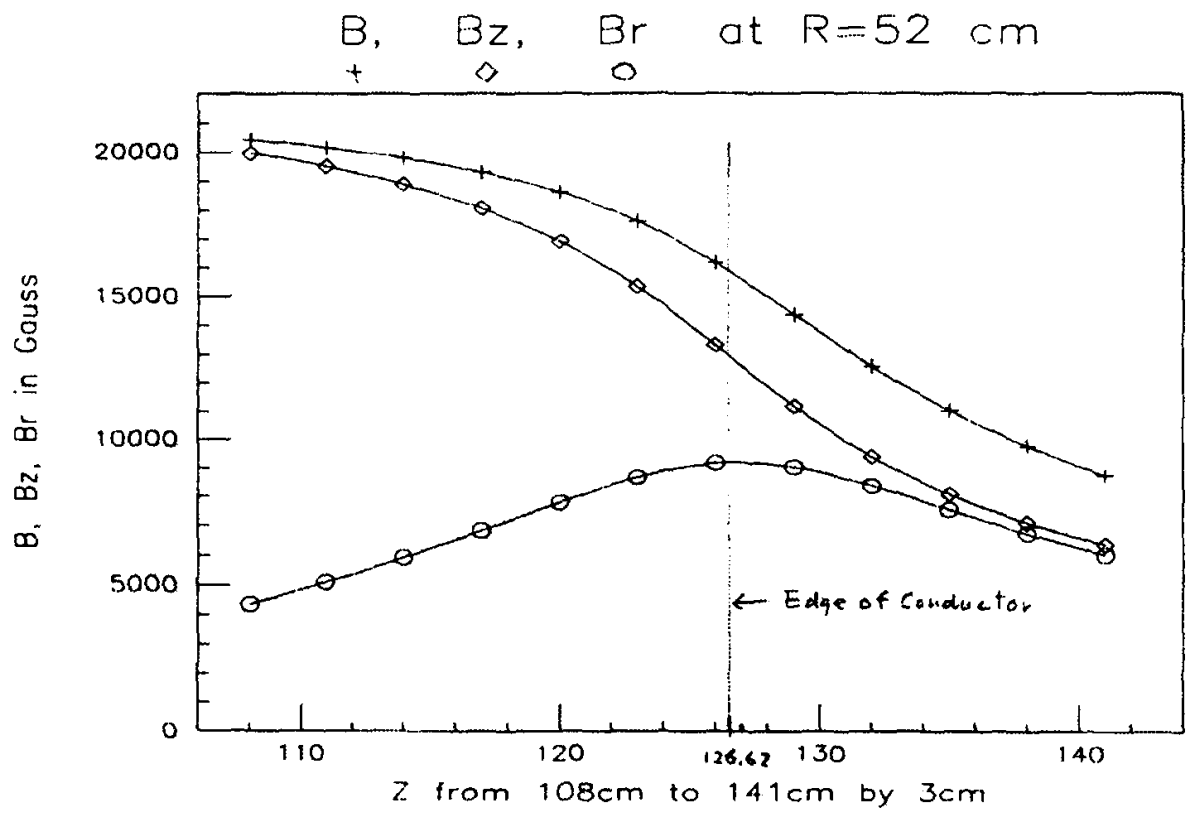

Fig. $12 \mathrm{~B}, \mathrm{Bz}$ and $\mathrm{Br}$ distributions at $\mathrm{R}=52 \mathrm{~cm}$ are shown 


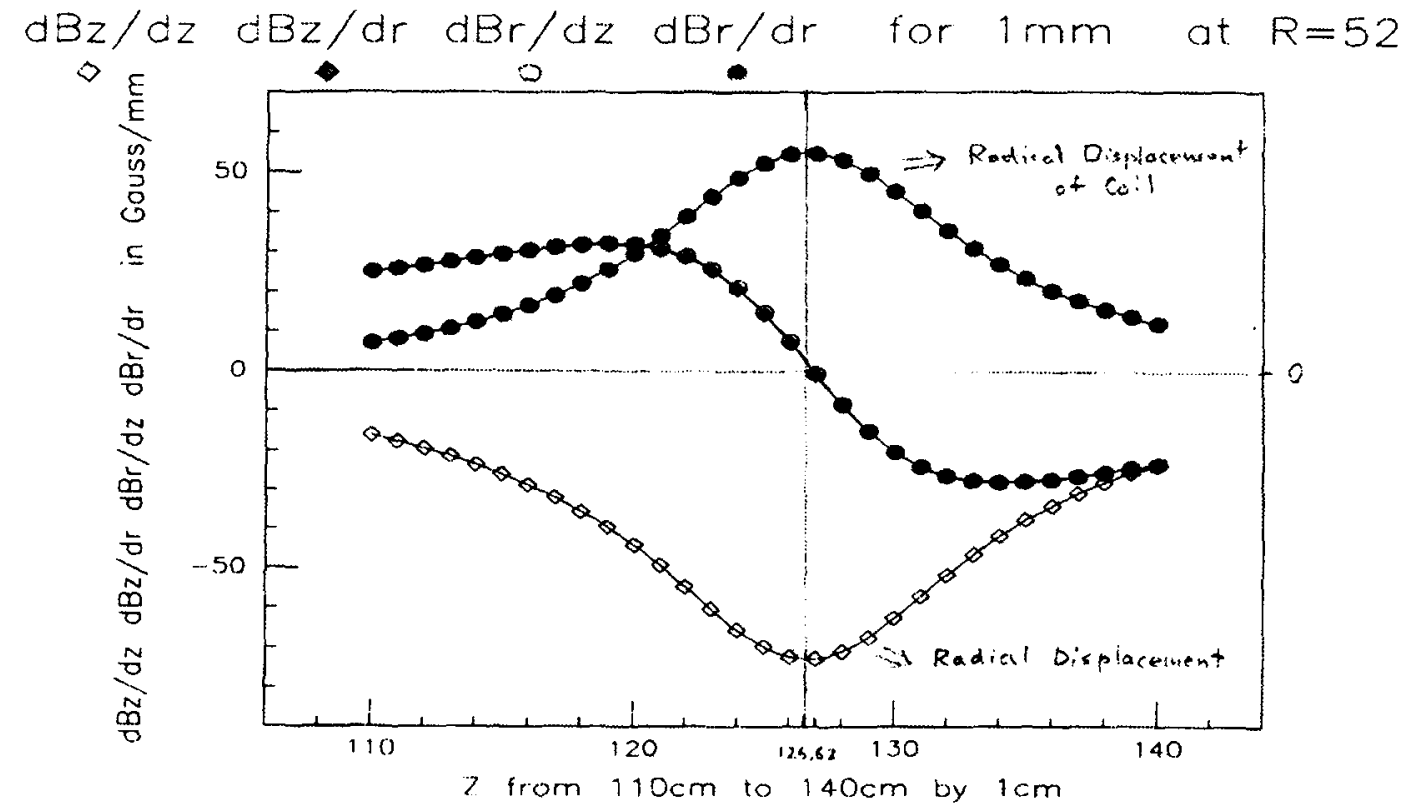

Fig. $13 \mathrm{dBz} / \mathrm{dz}, \mathrm{dBz} / \mathrm{dr}, \mathrm{dBr} / \mathrm{dz}$ and $\mathrm{dBr} / \mathrm{dr}$ (Gauss $/ \mathrm{mm}$ ) distributions for displacement of $1 \mathrm{~mm}$ at $R=52 \mathrm{~cm}$.

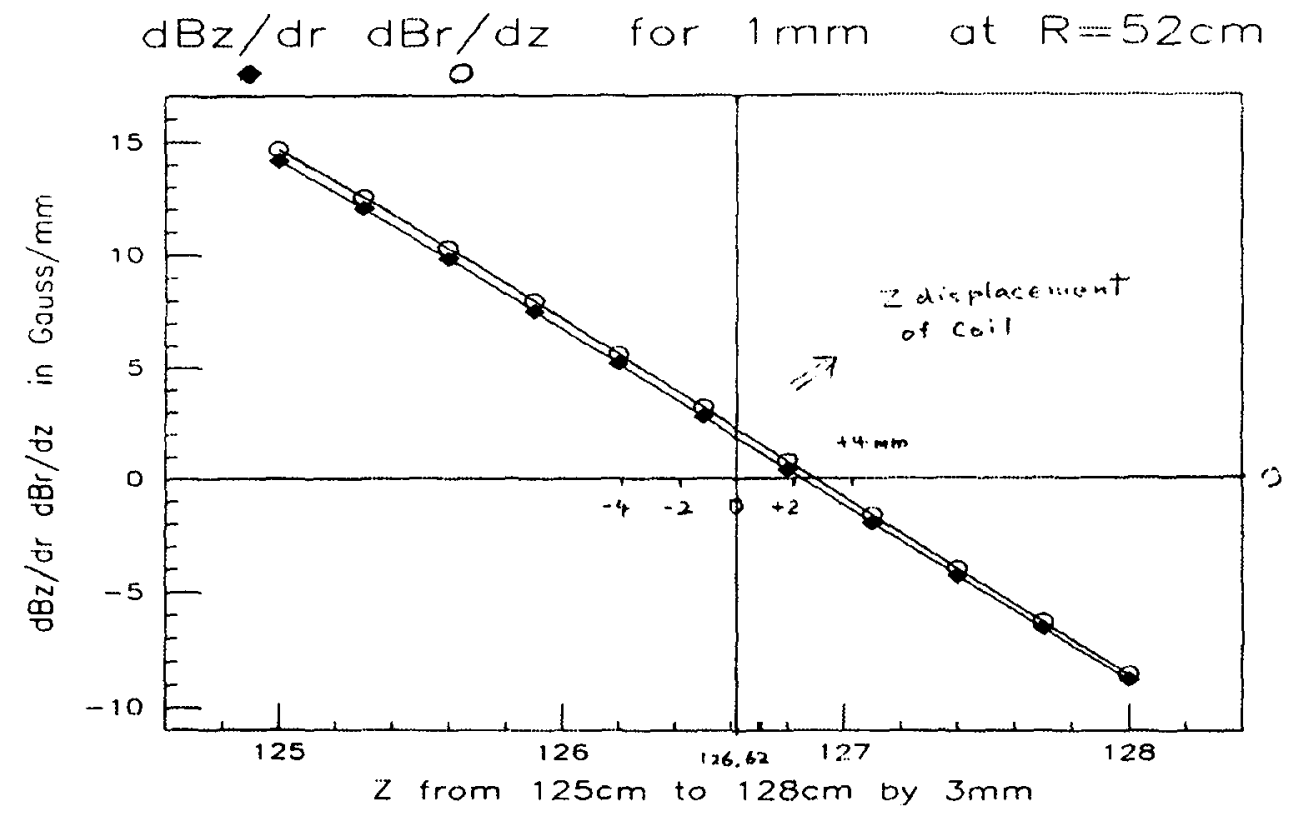

Fig. 14 Expanded $\mathrm{dBz} / \mathrm{dr}$ and $\mathrm{dBr} / \mathrm{dz}$ distributions at $\mathrm{R}=52 \mathrm{~cm}$ are shown around the conductor edge at $Z=126.62 \mathrm{~cm}$ 


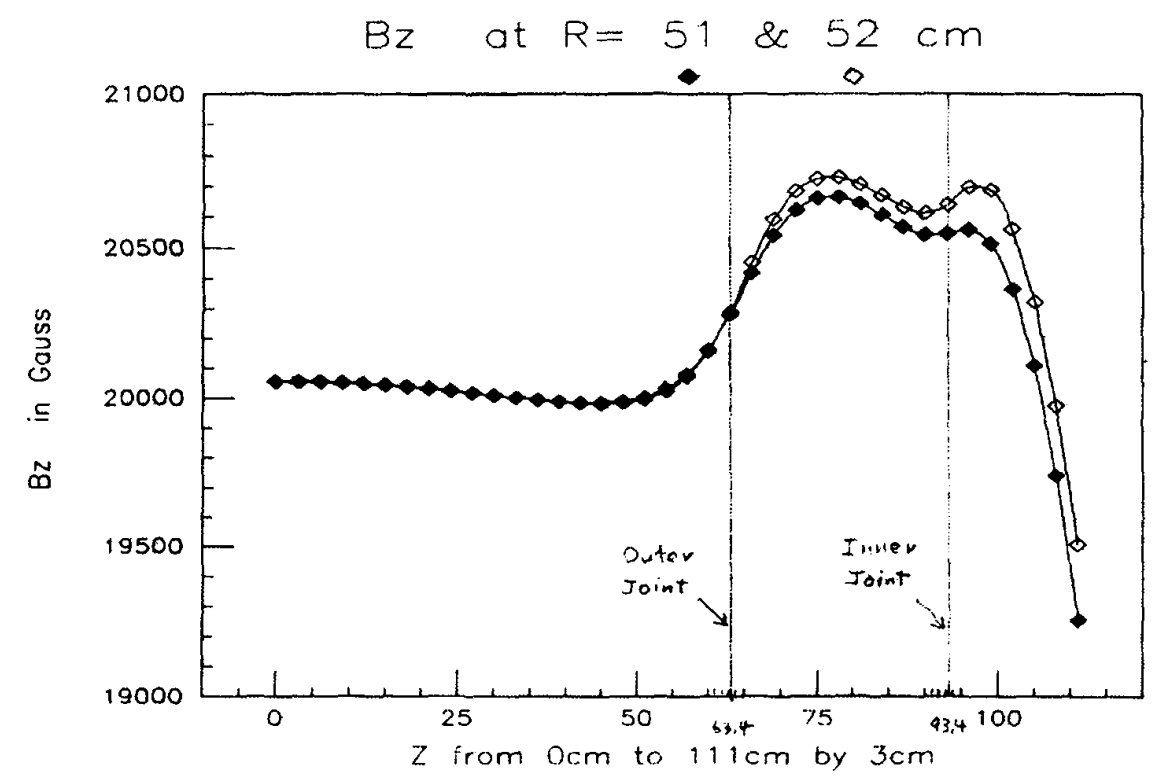

Fig 15. Bz distributions at $R=51$ and $52 \mathrm{~cm}$ with the location of the inner and outer conductor joints at $Z=93.4$ and $63.4 \mathrm{~cm}$ respectively.

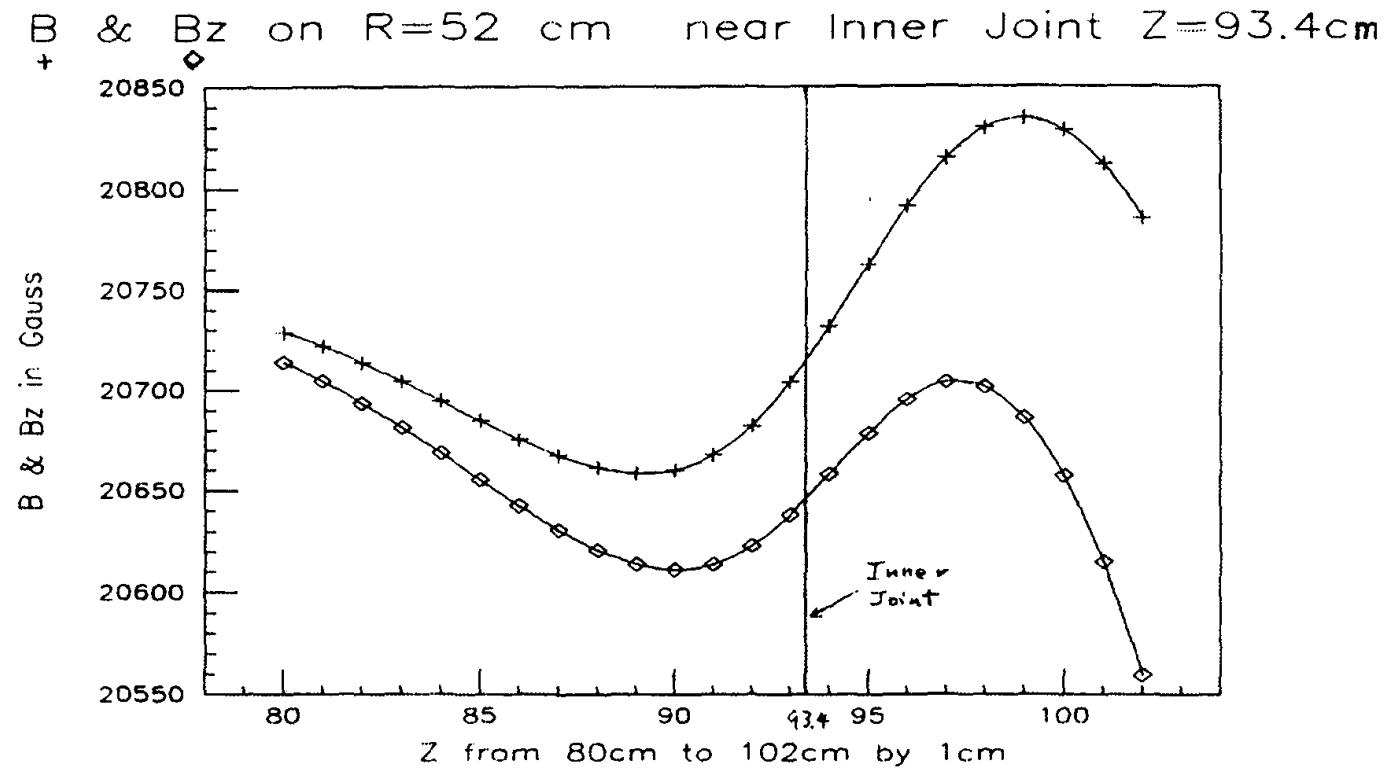

Fig. $16 \mathrm{~B}$ and $\mathrm{Bz}$ distributions at $\mathrm{R}=52 \mathrm{~cm}$ near the inner joint location at $\mathrm{Z}=93.4 \mathrm{~cm}$ 


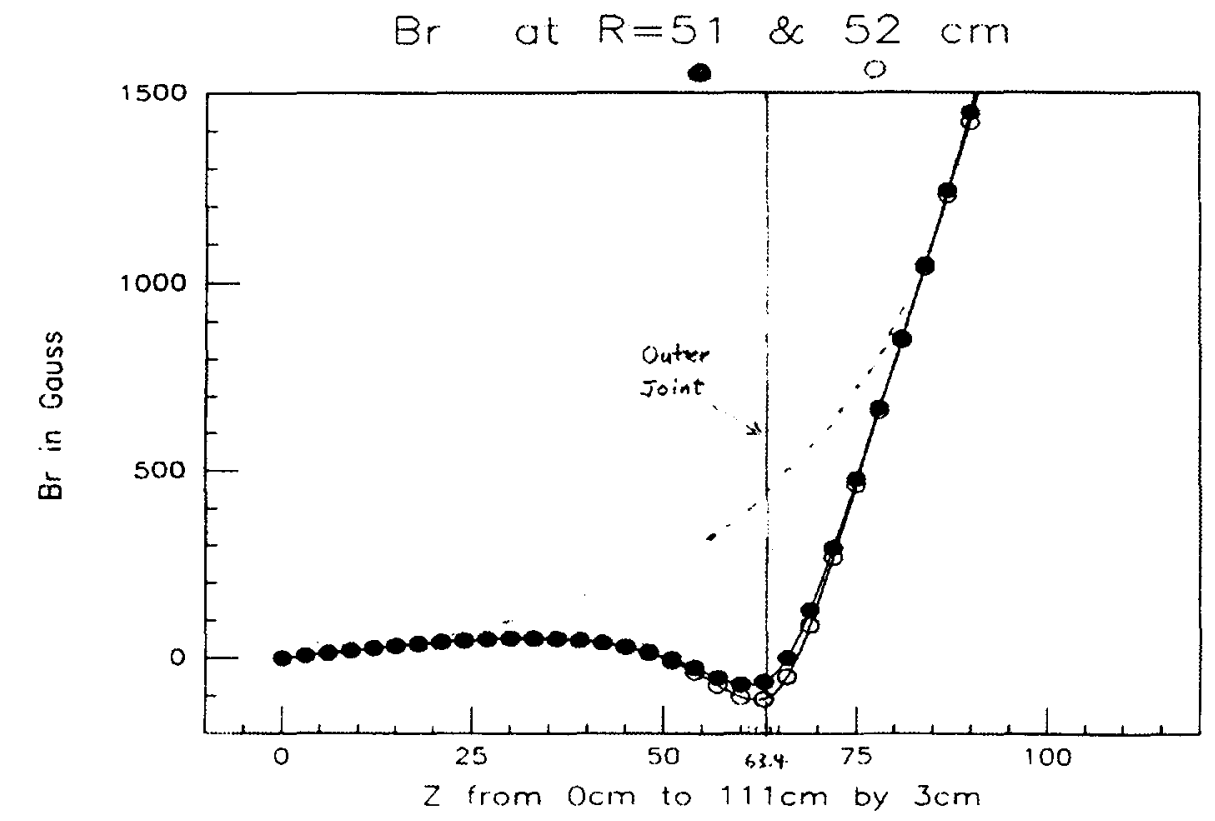

Fig. $17 \mathrm{Br}$ distributions at $\mathrm{R}=51$ and $52 \mathrm{~cm}$ with the location of the outer joint at $63.4 \mathrm{~cm}$ 